\title{
China expects leadership from rich nations
}

\author{
Greater emissions cuts by developed nations are the starting point for a successful climate deal at \\ Copenhagen in December says Jiahua Pan.
}

T o reach a successful climate agreement at the UN climate conference in Copenhagen, three fundamental elements (scientific evidence, political will and economic interest) and four practical elements (target setting for emissions reductions, adaptation, technology and financing) need to be addressed. Of these factors, negotiators will focus most attention, superficially, on mitigation targets. More fundamentally, however, they will focus on understanding economic impacts.

The Chinese perspective is that reaching a deal will depend largely on decisive mitigation action being taken by the developed nations. The developing nations will have every reason to follow suit if the rich nations demonstrate leadership and commit to more substantial cuts than they have offered so far.

There is already consensus on two of the fundamentals. The scientific conclusions outlined in the 2007 Fourth Assessment Report of the Intergovernmental Panel on Climate Change (IPCC) have been largely accepted by the global community. This year, the heads of the G8 countries expressed support for further climate-change actions: committing to limit global warming to $2{ }^{\circ} \mathrm{C}$ and proposing $50 \%$ global emissions cuts by 2050 from 1990 levels, with $80 \%$ cuts by industrialized nations (up from $50 \%$ a year earlier). It seems that there is no lack of political will. The only fundamental left is economic interest. Developed countries are concerned with immediate negative economic effects, whereas the developing countries are worried about their future well-being if they sign up to a legally binding, but unrealistic, target.

There are disagreements over all four practical elements, each linked to economic selfinterest. Adaptation, technology and financing are important for a climate deal but these are, at most, incentives for developing-country participation. All nations require adaptation, but developed countries have adaptive capacity whereas the developing ones do not. Financial resources are thus required to help the poorer countries to adapt. Technology transfer also entails the transfer of financial resources, because technologies have a market value.

So far, little external funding has been forthcoming. Some development assistance will be provided by rich nations, but this is far less than what is needed. The uncertainty over financing $\checkmark$ is a major barrier to a global climate deal.
Setting mitigation targets is the most challenging practical element. According to the 2007 Bali roadmap, the global community must have a long-term shared vision, and industrialized nations should make deeper emissions cuts by 2020 , whereas developing nations should take measurable, reportable and verifiable mitigation actions. The shared vision is often interpreted as a mitigation target for 2050 .

But are the cuts proposed by rich nations sufficient? The G8 proposal, although promoting a $50 \%$ global cut for 2050, avoids a target for 2020. The ratio of emissions between the Annex I (industrialized) nations and rest of the world is roughly 50:50. If Annex I nations cut their emissions by $80 \%$, developing nations will have to cut their emissions by some $20 \%$ in absolute terms from their current relatively low levels. In 2005, Annex I nations emitted almost five times the rate per capita of non-Annex nations. An $80 \%$ reduction would mean that by 2050 , per capita emissions for Annex I nations would drop to the 2005 levels for developing nations.

Yet to meet the G8 proposal, the per capita emissions of developing nations would have to be $20 \%$ lower than this level. This would mean that per-capita emissions in the developing world would always be lower than those in the developed nations, in the past, now and in the future. As fossil fuels are cheaper than carbon-free energy sources, developing countries argue that a premature shift to low-carbon energy may slow development. Only a slow and limited switch to low-carbon sources has been seen in rich nations, despite their technological

\section{CHINA'S EMISSIONS}

Carbon dioxide emissions scenarios to 2050 .

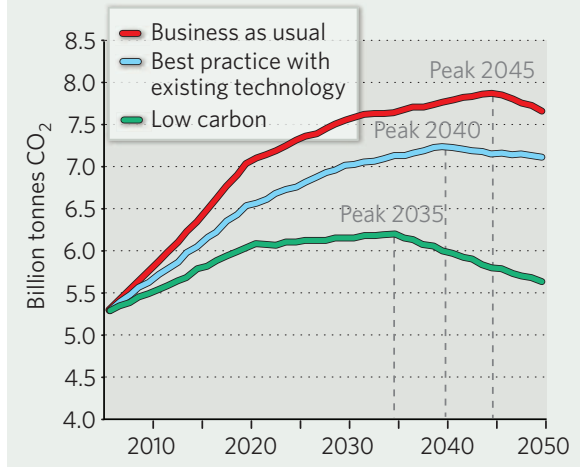

and financial advantages. Even so, China has been investing in low-carbon energy sources at a higher rate than most rich countries.

A 2020 target for cutting emissions is even more important but elusive. The IPCC recommends $25-40 \%$ cuts by 2020 for Annex I nations, and for developing countries to lower their emission pathways $15-30 \%$ from business as usual. A $40 \%$ cut by 2020 means decarbonization at twice the rate needed to meet the G8's 2050 target. But so far, none of the Annex I parties has voluntarily committed to a $40 \%$ target. The European Union, as front-runner, offered to boost its $20 \%$ cuts to $30 \%$, conditional on other parties' actions. The United States hasn't ruled out a 2020 target, but it is expected to be well below 25\%. Developing nations are willing to take mitigation action, but this is conditional on receiving technology and finance. Economics is preventing all nations from taking stronger action.

To achieve a solution, developed countries must show leadership in Copenhagen. They should promise cuts equal to, or deeper than, $40 \%$ for 2020. If the Annex I parties are unwilling or unable to do this, the rest of the world would be discouraged from taking serious action. A more likely outcome in Copenhagen would be a statement that the world intends to limit global warming to $2^{\circ} \mathrm{C}$ by 2050 . Emission reductions and mitigation actions for individual parties will have to be specified later.

Even so, the developing countries should prepare nationally appropriate mitigation plans for low-carbon development. These could include reducing carbon emissions per unit of gross domestic product and making tougher renewable-energy targets, both of which are compatible with development. It is in this regard that China and India as large developing economies can push forward the process. The road to and beyond Copenhagen will be tough, but there is no alternative. Jiahua Pan, Institute for Urban \& Environmental Studies, Chinese Academy of Social Sciences, 10 Xianxiao Hutong, Dongcheng District, Beijing, 100005, China e-mail: jiahuapan@163.com

See Editorial, page 1027, and online at www.nature. com/roadtocopenhagen. Join the discussion at go.nature.com/hzQ2MD. 